\title{
ANALISISI PERAN MEDIASI KEPUASAN NASABAH PADA HUBUNGAN DIGITAL MARKETING DAN BRAND LOYALTY PADA BANK JATENG CABANG WONOSOBO
}

\author{
Adityawan Fajar Firmanda ${ }^{1}$, Fitri Lukiastuti ${ }^{2}$ \\ Program Magister Manajemen, STIE Bank BPD Jateng \\ ${ }^{1)}$ adityawanfajar@gmail.com \\ ${ }^{2)}$ fitrilukiastuti@gmail.com
}

\begin{abstract}
ABSTRAK
Penggunaan teknologi dalam dunia pemasaran telah memberi banyak manfaat positf terhadap tingkat penjualan dan pemasaran produk perusahaan. Kemajuan teknologi menjadikan digitalisasi marketing menjadi solusi pemasaran di era sekarang. Selanjutnya, penelitian ini bertujuan untuk menganalisa implementasi dari penerapan digital marketing yang dilakukan oleh perusahaan untuk mengukur sejauh mana digital marketing dapat meningkatkan kepuasan nasabah sebuah lembaga keuangan dan berdampak terhadap brand loyakty dari perusahaan tersebut. Untuk penelitian ini dilakukan terhadap lembaga keuangan Bank Jateng Cabang Wonosobo dimana dilakukan pengambilan kuisioner berdasarkan dari sampel yang ttelah ditentukan yaitu nasabah pengguna produk dari Bank Jateng. Metode yang digunakan adalah survey deskriptif dengan metode analisis menggunakan Structural Equation Model (SEM) PLS. Hasil yang diperoleh menunjukkan bahwa implementasi digital marketing pada Bank Jateng Cabang Wonosobo melalui social media marketing, internet banking dan email marketing memberi dampak positif terhadap peningkatan kepuasan nasabah Bank Jateng Cabang Wonosobo dan digital marketing mampu memberi dampak positif terhadap brand loyalty. Dalam penelitian ini juga dapat disimpulkan bahwa secara tidak langsung kepuasan nasabah mampu memediasi hubungan antara digital marketing terhadap brand loyalty Bank Jateng Cabang Wonosobo.
\end{abstract}

Kata kunci: digital marketing, kepuasan nasabah, brand loyalty

\section{PENDAHULUAN}

Perkembangan dan kemajuan dunia teknologi saat ini telah menciptakan berbagai perubahan dari pola hidup dan perilaku para konsumen. Dimana kemajuan industri berbasis komunikasi dan teknologi informasi salah satunya yaitu internet telah membuat internet sebagai salah satu kebutuhan yang seolah tidak dapat terpisahkan dalam kehidupan manusia. Kehadiran internet telah banyak memberikan kemudahan bagi masyarakat dalam mengakses suatu informasi yang dibutuhkan.

Menurut Asosiasi E-commerce seluruh Indonesia, berdasarkan data yang ada penduduk Indonesia menghabiskan kurang lebih 55\% waktunya dalam menggunakan internet, dimana berdasarkan data yang ada masyarakat Indonesia menggunakan mobile phone selama 106 menit/hari dan 59 menit/hari untuk online menggunakan laptop (Kadarisman \& Ariyani, 2021).

Menurut (Pradiani, 2018), social media adalah sebuah teknik untuk memudahkan publikasi serta akses informasi interaksi social Dengan adanya teknologi digital, seluruh masyarakat perdesaan maupun perkotaan dapat menikmati layanan perbankan tanpa 
terkecuali. Promosi yang sebelumnya menggunakan media cetak dan elektronik, kini berganti menjadi promosi dengan menggunakan media sosial berbasis internet. Media sosial menjadi pilihan bagi konsumen dalam menghabiskan waktu secara online. Sehinngga media sosial sangat sesuai digunakan dalam pemasaran produknya ke konsumen.

Data dari American marketing Association (AMA) menyebutkan bahwa pemasaran digital sebagai proses dan aktivitas mengunakan teknologi digital untuk mengkomunikasikan, menciptakan serta menyampaikan nilai terhadap para konsumen (Kannan \& Li, 2017). Hendrawan et al., (2019) mengatakan bahwa pemasaran digital merupakan aktifitas dari pemasaran dengan branding dan memakai peran media sosial bersumber dari internet atau jejaring sosial seperti web site,blog dan e-mail. E-marketing adalah bagian dari e-commerce dimana digital marketing merupakan kegiatan pemasaran berbasis internet melalui computer atau telepon seluler dan menggunakan aplikasi media sosial network, sosial bookmarking, photo, website, email marketing, mobile aplication, ads sense,webinar. blog dan youtube.

Disrupsi digital menjadikan beberapa industri melakukan perubahan pada proses bisnisnya. Begitupula pada sektor perbankan, dimana perusahaan keuangan di Indonesa mulai mengeluarkan berbagai maca layanan berbasis digital banking, baik itu mobile banking mmaupun internet banking. Hal ini merupakan salah satu strategi untuk memperoleh nasabah-nasabah baru ataupun mempertahankan nasabah lama.

Pemasaran digital memungkinkan konsumen dalam memperoleh informasi terhadap produk ataupun jasa, melakukan transaksi perbankan menggunakan internet serta membuat perusahaan untuk memantau dan mempersediakan keinginan dan kebutuhan para calon pembeli tanpa batas waktu dan letak geografis. Digital marketing sebagai alur komunikasi dua arah yang mampu membuat awareness dan keterikatan masyarakat terhadap produk dan merek perusahannya.

Menurut (Keller \& Kotler, 2012) citra merupakan seperangkat keyakinan, ide serta kesan yang dimiliki oleh seseorang terhadap suatu obyek dengan demikian sebuah citra dapat terbentuk dari apa yang dirasakan dan dilihat oleh konsumen atau nasabah terhadap tindakan atau pelayanan perusahaan yang diberikan untuk nasabah. Dimensi citra sendiri terbagi menjadi 4, yaitu reputation, recognition, affinity, dan brand loyality dimana dimensi dari citra tidak dapat berdiri sendiri melainkan sebuah perpaduan dari kegiatan perusahaan dalam rangka memberikan pelayanan secara langsung maupun tidak langsung kepada nasabah untuk melakukan kegiatan yang berhubungan dengan operasional ataupun identitas anggota perusahaan. Sehingga dengan adanya kegiatan itu, dapat membuat kesan terhadap para nasabah mengenai apa yang dilakukan oleh perusahaan.

Melihat pergeseran budaya pemasaran secara konvensional kearah digital marketing, menjadi suatu peluang bagi PT BPD Jawa Tengah atau disebut Bank Jateng dalam mempromosikan produk dan layanannya secara lebih maksimal guna menjamin kepuasan nasabah dengan layanan yang semakin memudahkan nasabah dalam melakukan transaksi keuangan.

Kepuasan nasabah merupakan strategi yang bisa digunakan oleh perusahan dalam meningkatkan kepuasan nasabah, diantaranya dengan relationship marketing dan superior customer service (Fandi \& Gregorius, 2012). Ketika nasabah merasa puas secara tidak langSung akan memberi dampak positif dalam peningkatan citra perusahaan dan menampilkan corporate image yang baik dihadapan nasabah sebagai pengguna jasa perbankan. 
Berdasarkan data yang diperoleh, bersumber pada Laporan Keuangan Berkelanjutan Periode 2019 yang dikutip langsung dari http://www.bankjateng.co.id, menyatakan bahwa sesuai dengan komitmen Bank Jateng mengenai kepuasan dan loyalitas para nasabah maka dilakukan Survey Kepuasan Nasabah dengan aspek penilaian berdasarkanpada indeks kepuasan dan loyalitas Produk Bank Jateng pada tahun 2019 mencapai nilai indeks 5,03 dari skala 1-6 dan masuk kedalam kategori "Puas". Adapun indeks loyaitas tergadap Produk Bank Jateng meraih capaian nilai indeks 4,96 dari skala 1-6 dengan prediksi "Loyal". Selanjutnya dalam tabel tersebut terdapat Indikator kelengkapan dan kecanggihan teknologi internet banking mencapai skor 4,66, kemudahan menggunakan internet banking mencapai skor 4,82 dan kemudahan mendapatkan informasi perbankan diberbagai media dengan skor 4,0. Adapun hasil penilaian indeks Kualitas Pelayanan pada tahun 2019 memperoleh skor sebesar 70,82 \% yang dimana meningkat dari perolehan skor tahun 2018 yaitu sebesar 60,58 \%. Pecapaian penilaian tersebut membuat Bank Jateng meraih peringkat 1 sebagai Best Information Technology-2019 Kategori BPD dari Ekonomic Review, Juara 1 The Best Indonesia Sales \& Marketing Award III 2019 dari Ekonomic Review, Juara 2 Satisfaction Bank Pembangunan Daerah dari Infobank - MRI dan lain-lain.

Melalui penelitian ini, penulis selanjutnya melakukan penelitian dengan melakukan observasi secara langsung pada kantor Bank Jateng Cabang Wonosobo sebagai salah satu Kantor Cabang Bank Jateng dimana observasi ini dilakukan untuk meneliti mengenai "implementasi digital marketing untuk meningkatkan kepuasan nasabah dan berdampak pada citra lembaga keuangan perbankan Bank Jateng Cabang Wonosobo". Berdasarkan latar belakang tersebut, maka permasalahan yang dapat dirumuskan adalah sebagai berikut:

1. Bagaimana pengaruh digital marketing terhadap kepuasan nasabah Bank Jateng Cabang Wonosobo?

2. Bagaimana pengaruh digital marketing terhadap citra perbankan Bank Jateng Cabang Wonosobo?

3. Bagaimana pengaruh kepuasan nasabah terhadap citra perbankan Bank Jateng Cabang Wonosobo?

4. Bagaimana pengaruh mediasi kepuasan nasabah terhadap hubungan digital marketing dan citra perbankan Bank Jateng Cabang Wonosobo.?

\section{LANDASAN TEORI DAN PENGEMBANGAN HIPOTESIS}

\section{Digital Marketing}

Banyaki definisi yang telah diidentifikasi dalam penelitian sebelumnya yang berkaitan dengan pemasaran digital. Salah satu definisinya adalah pemasaran yang memanfaatkan perangkat elektronik seperti komputer pribadi, smartphone, ponsel, dan konsol game untuk melibatkan pemangku kepentingan menjadi bagian dari prosedur. Teknik pemasaran digital memiliki kekuatan untuk mengulang beberapa aspek komunikasi pemasaran dan saluran media kuno dan, dengan demikian, mereka dapat memperluas bauran pemasaran. Kampanye digital bersifat spesifik dan merupakan bagian dari bauran komunikasi pemasaran (Omar \& Atteya, 2020).

Digital Marketing membantu sebuah perusahaan dalam mempromosikan dan memasarkan produk maupun jasa yang mereka punya. digital marketing juga dapat membuat atau membuka pasar-pasar baru yang sebelunya tertutup karena adanya keterbatasan waktu, cara komunikasi, maupun jarak (Prabowo, 2018). Digital marketing 
adalah kegiatan marketing termasuk branding yang menggunakan berbagai media berbasis web seperti blog, web site, e-mail, adwords, ataupun jejaring sosial (Josua Tarigan \& Sanjaya, 2013).

Menurut (Syafikarani, 2021), digital marketing memiliki beberapa manfaat dalam kegiatan pemasaran sebuah perusahaan untuk menjual produk maupun jasa layanannya diantaranya sebagai berikut :

1. Jangkauan lebih luas. Digital marketing memiliki jangkauan geografi yang lebih luas dalam penyebaran produk dengan jangkauan jaringan dunia melalui internet.

2. Kecepatan Penyebaran. Strategi pemasaran melalui media digital dapat menghemat banyak waktu karena kecepatan per detiknya. Kegiatan digital marketingpun dapat diukur secara real-time dan tepat waktu.

3. Kemudahan evaluasi. Kegiatan pemasaran media online memudahkan konsumen untuk lebh mudah memperoleh informasi mengenai produk lama produk dilihat, penjualan yang terjual dari iklan yang ditampilkan serta lainnya dapat dengan mudah diperoleh oleh pihak pemasar.

Ada empat dimensi digital marketing yang membantu keberhasilan usaha yaitu interaktif, program insentif, disain web dan biaya (Young Kim \& Kim, 2004). Penelitian sebelumnya menemukan bahwa metode pemasaran digital memungkinkan sektor perbankan menjangkau pelanggan yang belum terjangkau atau underbanked dan memberdayakannya untuk berinteraksi dengan audiens yang ingin mereka targetkan. Begitu pula dengan ekspektasi digital yang tinggi, nasabah juga ingin melihat konten online yang sesuai dengan apa yang mereka cari di sektor perbankan, yang meliputi internet banking, social media marketing, email marketing (Amelda et al., 2021).

\section{Kepuasan pelanggan di Sektor Perbankan}

Kepuasan pelanggan adalah salah satu yang paling penting faktor untuk setiap lembaga keuangan, terutama untuk sektor perbankan. Bisnis perbankan tidak dapat menghasilkan keuntungan dan bertahan lama tanpa kepuasan nasabah (Rapitasari, 2016; Andriyani \& Ardianto, 2020). Kepuasan pelanggan adalah ide komunal kinerja layanan pelanggan dari sebuah perusahaan bank. Kepuasan pelanggan adalah tingkat pencapaian keseluruhan harapan pelanggan (Gazi et al., 2021), yang diukur dengan menentukan perbedaan antara keinginan layanan dan kinerja layanan yang sebenarnya. Ada lima jenis kepuasan nasabah yang unik di sektor perbankan, yaitu, kesenangan, kebaruan, kelegaan, kepuasan, dan kejutan (Oliver \& Swan, 1989). (Gazi et al., 2021) menemukan bahwa empati, jaminan, keandalan, daya tanggap, dan berwujud berpengaruh positif terhadap kepuasan pelanggan di sektor perbankan kecuali kompetensi karyawan. Pelanggan yang puas menjadi pelanggan yang loyal (Glowa, 2014) dan, pada gilirannya, pelanggan yang loyal mengarah pada penjualan yang lebih tinggi dan dengan demikian meningkatkan pengembalian finansial perusahaan (J Tarigan \& Elsye Hatane, 2019).

Namun, beberapa peneliti telah mengidentifikasi faktor-faktor yang mempengaruhi kepuasan pelanggan. Diantaranya, kualitas pelayanan adalah faktor yang paling berpengaruh, yang melibatkan lima dimensi seperti bukti fisik, keandalan, jaminan, daya tanggap, dan empati (Fida et al., 2020) dan (Pakurár et al., 2019).

Di sektor perbankan, nasabah tingkat kepuasan memisahkan dari satu bank ke bank lain (Hamad, 2018). Kepuasan nasabah bank mempengaruhi tampilan visual yang menarik, pembicaraan positif tentang bank kepada orang lain (Setyaning \& Nugroho, 2020), dan perilaku sopan staf perbankan (Panjaitan, 2017). Beberapa peneliti berpendapat bahwa kepuasan nasabah bank dijamin dengan kualitas layanan (Tabash et al., 2019; Ati et al., 2020; (Nambiar et al., 2019). (Sulaeman, 2015) mengamati bahwa 
kepuasan nasabah bank dipengaruhi secara positif dan signifikan oleh kualitas layanan multidimensi. (Ati et al., 2020) dan (Supriyanto et al., 2021)) mengidentifikasi hasil yang sama. Sebagian besar penelitian menemukan bahwa kualitas layanan merupakan cikal bakal kepuasan pelanggan (Garepasha et al., 2020) dan (Ali et al., 2021).

\section{Loyalitas Merek (Brand Loyalty)}

Loyalitas merek dapat dikonseptualisasikan sebagai dimensi akhir dari resonansi merek. (Giovanis \& Athanasopoulou, 2018) mengatakan bahwa loyalitas merek dianggap memiliki dua dimensi: loyalitas sikap dan perilaku. Baik peneliti dan praktisi sepakat bahwa loyalitas merek sebagai faktor penting untuk kelangsungan hidup dan kemakmuran perusahaan karena berkontribusi pada peningkatan volume pembelian kembali dan akuisisi yang lebih baik. Oleh karena itu, mengungkapkan loyalitas merek menjadi substansial aset non material untuk sebuah merek (Jiang \& Zhang, 2016).

Loyalitas merek didefinisikan sebagai kecenderungan pelanggan untuk terus memilih satu merek daripada produk bermerek yang bersaing (Kusuma et al., 2020). (Bisschoff, 2020a) menjelaskan bahwa loyalitas merek menghasilkan pelanggan yang rela menunggu dalam antrean panjang untuk membeli produk tertentu, pelanggan yang akan melakukan perjalanan jauh, dan pelanggan yang pada dasarnya kebal terhadap promosi produk pesaing yang sifatnya serupa. Sebuah perusahaan tidak hanya menghemat dalam memperoleh pelanggan baru, tetapi mampu melayani pelanggan yang sudah ada yang kembali lagi dan lagi karena mereka memiliki hubungan yang setia dengan merek tertentu; ini sepadan dengan pangsa pasar dan peningkatan profitabilitas.

Selanjutnya, nilai loyalitas merek tidak hanya terletak pada niat membeli kembali pelanggan, tetapi juga karena pelanggan setia merek bersedia membayar harga yang lebih tinggi dan kurang sensitif terhadap fluktuasi harga (Nuseir, 2016 dan Ngabiso et al., 2021). Hal ini baru saja dikonfirmasi oleh (Casteran et al., 2019) yang menyatakan bahwa harga tidak lagi menjadi kriteria pengambilan keputusan konsumen yang dominan di Afrika Selatan; merek dan loyalitas merek sekarang sangat mempengaruhi proses pengambilan keputusan

\section{Pengembangan Hipotesis}

\section{a. Pengaruh Digital Marketing terhadap Loyalitas Merek (Brand Loyalty) Bank Jateng Cabang Wonosobo}

Tetap kompetitif di lanskap bisnis yang bergerak cepat saat ini membutuhkan strategi media sosial yang solid. Perusahaan mempekerjakan pakar dan konsultan media sosial untuk memutuskan konten dan karakteristik penawaran dan aktivitas mereka di lingkungan media sosial sehingga hati dan pikiran konsumen ditangkap dan loyalitas merek mengikuti (Erdoğmuş \& Çiçek, 2012). Dalam perspektif ini, tujuan dari makalah ini adalah untuk menjelaskan perspektif konsumen tentang efek media sosial pada loyalitas merek sehingga implikasi dapat ditarik bagi perusahaan untuk menyusun kegiatan pemasaran media sosial yang efektif untuk merek mereka. Penelitian oleh eMarketer telah menunjukkan bahwa konsumen mengunjungi situs media sosial untuk mengikuti produk merek dan kampanye promosi (Mangold \& Faulds, 2009); (Erdoğmuş \& Çiçek, 2012). Misalnya, Pepsi dan Coca-Cola keduanya menerapkan program loyalitas pelanggan online untuk melibatkan pelanggan dengan menawarkan promosi khusus, gratis. Selain itu, pelanggan melihat situs media sosial sebagai saluran layanan, di mana mereka dapat terlibat secara real-time dengan bisnis. Namun, konsumen lebih suka melihat konten terupdate di media sosial. Dengan demikian, Google telah mengubah 
algoritma sistem pencarian mereka untuk memungkinkan pelanggan melihat konten yang diperbarui terlebih dahulu (Khandelwal et al., 2018). Pelanggan yang terpapar banyak pesan merek di platform media sosial menyaring konten yang tidak relevan bagi mereka (Magotra et al., 2018). Oleh karena itu, menyediakan konten yang relevan dan diperbarui adalah salah satu strategi paling penting untuk mengelola merek di media sosial dengan sukses. Popularitas platform media sosial dan konten di antara teman-teman adalah alasan penting lainnya bagi pelanggan untuk terlibat dengan merek di media sosial. Karena ada banyak platform media sosial dan tidak mungkin untuk melibatkan semuanya, pemasar harus menganalisis audiens target mereka dan memutuskan untuk berpartisipasi dalam platform yang paling efektif untuk berkomunikasi dengan mereka. Selain itu, menyediakan aplikasi seluler memungkinkan pelanggan untuk terlibat dengan merek setiap hari dan menciptakan loyalitas merek (Murtiningsih \& Murad, 2016). Berdasarkan hal tersebut, maka diajukan hipotesis sebagai berikut :

H1 : digital marketing mempunyai pengaruh yang positif terhadap loyalitas merek.

\section{b. Pengaruh Digital Marketing terhadap Kepuasan Nasabah Bank Jateng Cabang Wonosobo}

Perusahaan harus mengikuti perkembangan teknologi digital karena akan membawa dinamika baru dalam perilaku bisnis dan merupakani alat yang sangat diperlukan untuk kesuksesan bisnis. Penggunaan media digital dapat memperkuat kepuasan pelanggan dan memungkinkan perusahaan untuk tetap berhubungan dengan pelanggan mereka dan melayani mereka secara efektif. Kepuasan pelanggan akhir-akhir ini mendapatkan perhatian yang signifikan dalam konteks pergeseran paradigma dari pemasaran transaksional ke pemasaran relasional. Pemeriksaan studi sebelumnya yang dilakukan di bidang pemasaran digital mengungkapkan banyak fokus pada bagaimana perusahaan dapat memanfaatkan revolusi ini (Hudson et al., 2016); (Royle \& Laing, 2014; Yamin, 2017). Lainnya yang memprioritaskan kepentingan dan kekuatannya bagi konsumen (Labrecque et al., 2013; Dwivedi et al., 2021; Wang \& Tang, 2003; Yasmin et al., 2015). Ini membuktikan bahwa sedikit atau tidak ada karya yang diterbitkan telah dilakukan untuk menguji pengaruh pemasaran digital pada kepuasan pelanggan di bank uang deposito Nigeria. Oleh karena itu, penelitian ini bertujuan untuk mengisi kesenjangan tersebut. Sementara revolusi digital mempengaruhi semua sektor dan profesi, pengaruhnya dalam pemasaran adalah yang paling mendalam. Ini karena pemasar bertanggung jawab untuk mengembangkan strategi untuk menarik dan mempertahankan pelanggan yang kebutuhannya terus berubah (Desereacute \& Thakane, 2013; Stanley \& Chinelo, 2017; dan Pradiatiningtyas et al., 2020). Berdasarkan uaraian tersebut maka diajukan hipotesis sebagai berikut :

$\mathrm{H} 2$ : digital marketing mempunyai pengaruh yang positif terhadap kepuasan nasabah.

\section{c. Pengaruh Kepuasan Nasabah terhadap Brand Loyalty Bank Jateng Cabang Wonosobo}

(Veloutsou, 2015) dan (Sundaram et al., 2017) menyatakan bahwa besarnya tingkat kepuasan yang diperoleh pelanggan dari pengalaman menggunakan produk atau jasa dapat mempengaruhi ikatan yang dibangun antara pelanggan dan merek, oleh karena itu kepuasan berpengaruh positif terhadap loyalitas merek. Kepuasan dapat menjadi salah satu elemen untuk mengarahkan pelanggan untuk membeli kembali, kemungkinan dimoderatori oleh kepuasan, relasional, dan karakteristik pasar (Al-msallam, 2015). 
Menurut (Awan \& Rehman, 2014), kepuasan dalam berbagai konteks dapat diterjemahkan menjadi loyalitas merek ketika kepuasan pelanggan benar-benar dirasakan tinggi.

Pemasar yang ingin menarik/ mempertahankan pelanggan harus melakukan yang terbaik untuk membangkitkan perasaan puas pelanggan (Pramita, 2019). Menurut mereka hubungan antara kepuasan pelanggan adalah positif dan paling signifikan dengan loyalitas merek. Berdasarkan hal tersebut, maka diajukan hipotesis sebagai berikut :

H3 : Kepuasan nasabah mempunyai pengaruh yang positif terhadap loyalitas merek.

\section{d. Pengaruh Mediasi Kepuasan Nasabah terhadap Hubungan Digital Marketing dan Brand Loyalty Bank Jateng Cabang Wonosobo}

Jaringan digital menawarkan fleksibilitas dan kemudahan untuk menjangkau pelanggan dalam jumlah besar melalui berbagai atribut (Brakus et al., 2009). Pemasaran digital tampil melalui berbagai cara seperti aplikasi online, platform dan media virtual, di mana, ada banyak pendekatan mengenai video, blog, gambar, rekaman atau podcast, dll. Beberapa saluran yang terkenal dan efektif antara lain Facebook, Youtube, Twitter, Instagram, dll..

Menyadari semakin berkembangnya platform media sosial, pemasar telah mampu mengadaptasi saluran pemasaran yang lebih fleksibel dan lebih inovatif daripada saluran pemasaran tradisional. Kemudian, seiring dengan peningkatan signifikan dalam penggunaan media sosial dan internet, semakin banyak perusahaan bergabung di dunia media sosial dengan tujuan untuk mendorong interaksi online antar pengguna dan melibatkan pelanggan dengan merek (Şahin et al., 2011).

Tidak hanya merek dan perusahaan, pengusaha individu dan organisasi pemerintah juga berpartisipasi untuk tetap berhubungan dengan pengguna potensial. Di sisi lain, pelanggan mengikuti satu merek di situs sosial untuk tetap mendapat informasi lengkap tentang produk terbaru atau promosi diskon, pembaruan, dan berita relevan tentang merek tersebut. Umumnya, pemasaran media sosial mempersempit kesenjangan antara konsumen dan pemasar dengan memberikan peluang komunikasi sehingga hubungan konsumen-pemasar dapat melepaskan diri dari status berbasis komersial tetapi menjadi lebih pribadi dan terkonsentrasi (Arum Wahyuni Purbohastuti, 2017)

Melalui komunitas online, perusahaan dapat memperoleh perspektif dan umpan balik yang berharga dari pelanggan yang tidak mudah mereka akses dengan cara biasa, selain itu, mereka juga meningkatkan kesadaran merek dan pengakuan secara ekonomi. Hasil lain yang dapat bermanfaat bagi merek-merek ini adalah bahwa hubungan antara dua pihak dapat meningkatkan kepuasan pelanggan serta mendorong berita positif dari mulut ke mulut pada komunitas merek online (Schau et al., 2009) dan (Ong et al., 2018). Berdasarkan hal tersebut, maka diajukan hipotesis sebagai berikut :

H4 : Kepuasan Pelanggan Mediasi Hubungan Digital Marketing dan Brand Loyalty. 


\section{MODEL PENELITIAN}

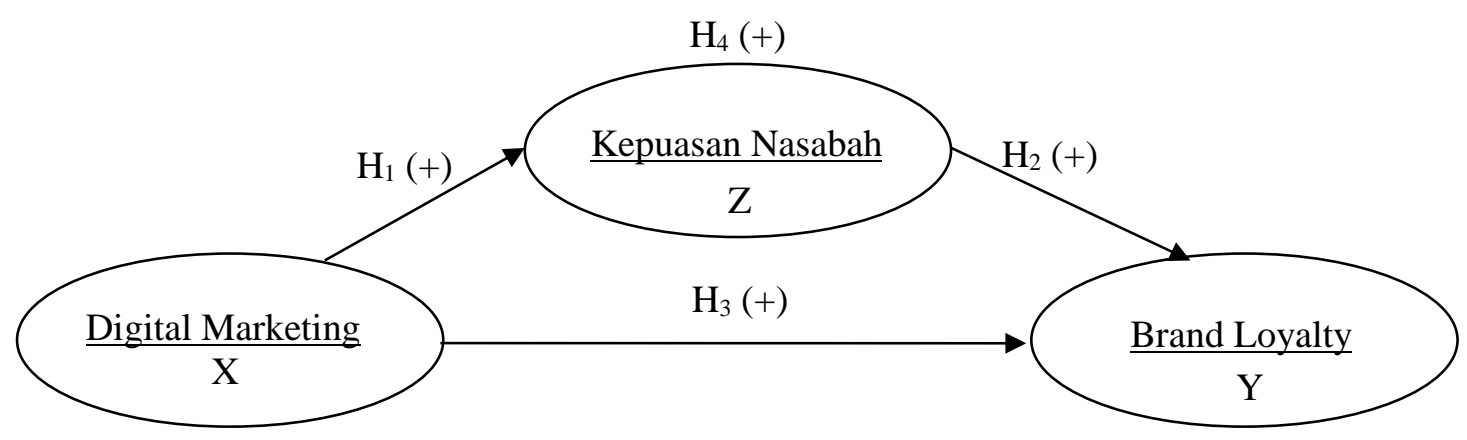

Gambar 1. Model Penelitian

\section{METODE PENELITIAN}

\section{Populasi dan Sampel}

Populasi dalam penelitian ini adalah seluruh nasabah Bank Jateng Cabang Wonosobo pengguna fitur digital marketing yang masih aktif baik nasabah simpanan maupun pinjaman sebanyak 53.474 orang. Jumlah sampel ditetapkan dengan menggunakan rumus Slovin sebanyak 100 orang nasabah. Teknik sampling yang digunakan adalah non probality sampling, yaitu pemilihan sampel secara tidak acak dan elemen-elemen populasi tidak memiliki kesampatan yang sama untuk terpilih menjadi sampel (Sugiyono, 2010). Alat analisis menggunakan analisis PLS (Partial Least Squares) untuk menganalisis ada tidaknya hubungan antar variabel (M Anwar, 2019).

\section{Pengukuran Variabel}

Digital Marketing : cost, incentive program, site design, dan interactive(Young Kim \& Kim, 2004). Kepuasan Nasabah : kualitas produk, faktor kemudahan, kualitas pelayanan, dan faktor emosional (Sari et al., 2021). Brand loyalty : trust, expertise, consistency, personalize experience, dan valuable content (Bisschoff, 2020b).

\section{HASIL DAN PEMBAHASAN}

\section{HASIL}

\section{Identitas Responden}

Tabel 1 : Identitas Responden

\begin{tabular}{llcc}
\hline No & Keterangan & Jumlah & \% \\
\hline 1 & Jenis Kelamin & & \\
& Laki-laki & 58 & $58 \%$ \\
& Perempuan & 42 & $42 \%$ \\
2 & Usia & & \\
& $21-26$ tahun & 14 & $14 \%$ \\
& $27-32$ tahun & 24 & $24 \%$ \\
& $33-42$ tahun & 41 & $41 \%$ \\
& $>45$ tahun & 21 & $21 \%$ \\
\hline
\end{tabular}

Sumber : data primer diolah, 2021. 


\section{a. Uji Validitas dan Reliabilitas}

Suatu instrumen penelitian dikatakan valid jika nilai koefisien korelasinya sama dengan atau lebih besar dari 0,30. Semua instrumen variabel dalam penelitian ini memiliki koefisien korelasi diatas 0,30 yang berarti telah memenuhi validitas persyaratan instrumen. Suatu variabel dikatakan reliabel jika memiliki nilai Cronbach's Alpha $(\alpha)$ di atas 0,70 . Sampel yang digunakan untuk menguji reliabilitas instrumen adalah 100 orang nasabah. Semua instrumen variabel dalam penelitian ini memiliki nilai Cronbach's Alpha $(\alpha)$ di atas 0,70 . Artinya semua instrumen dalam penelitian ini reliabel.

b. Evaluasi Model Pengukuran (Outer Model)

\section{Convergent Validity}

Table 2 : Loading Factors I

\begin{tabular}{lccc}
\hline & Brand Loyalty & Digital_Marketing & Kepuasan_Nasabah \\
\hline BL1 & 0,877 & & \\
BL2 & 0,728 & & \\
BL3 & 0,793 & & \\
BL4 & 0,867 & & \\
BL5 & 0,685 & & \\
BL6 & 0,888 & & \\
BL7 & 0,866 & & \\
BL8 & 0,734 & & \\
DM1 & & 0,654 & \\
DM2 & & 0,787 & \\
DM3 & & 0,856 & \\
DM4 & & 0,806 & \\
DM5 & & 0,831 & \\
DM6 & & 0,862 & \\
DM7 & & 0,563 & 0,733 \\
DM8 & & 0,71 & 0,768 \\
KN1 & & & 0,859 \\
KN2 & & & 0,822 \\
KN3 & & & 0,807 \\
KN4 & & & 0,728 \\
KN5 & & & \\
KN6 & & & \\
KN7 & & & \\
\hline
\end{tabular}

Sumber: data primer diolah, 2021

Tabel 2 menunjukkan bahwa seluruh nilai loading factor pada masing-masing indikator mempunyai nilai $\geq 0,7$ kecuali BL5, DM1, DM7 dan KN7. Indikator yang memiliki nilai loading factor dibawah 0,7 berarti tidak valid dan harus di drop dari penelitian. 
Tabel 3 : Loading Factors II

\begin{tabular}{lccc}
\hline & Brand Loyalty & Digital_Marketing & Kepuasan_Nasabah \\
\hline BL1 & 0,895 & & \\
BL2 & 0,682 & & \\
BL3 & 0,813 & & \\
BL4 & 0,874 & & \\
BL6 & 0,878 & & \\
BL7 & 0,884 & & \\
BL8 & 0,757 & & \\
DM2 & & 0,797 & \\
DM3 & & 0,854 & \\
DM4 & & 0,847 & \\
DM5 & & 0,876 & \\
DM6 & & 0,905 & \\
DM8 & & 0,67 & 0,725 \\
KN1 & & & 0,759 \\
KN2 & & & 0,864 \\
KN3 & & & 0,827 \\
KN4 & & & 0,831 \\
KN5 & & & 0,743 \\
KN6 & & & \\
\hline
\end{tabular}

Sumber : data primer diolah, 2021.

Tabel 3 menunjukkan bahwa masih ada nilai loading factor yang dibawah 0,7 yaitu BL2 dan DM8. Indikator yang memiliki nilai loading factor dibawah 0,7 berarti tidak valid dan harus di drop dari penelitian. Berikut adalah nilai loading factors setelah indkator yang tidak valid di drop sebagaimana table 4 .

Tabel 4 : Loading Factor III

\begin{tabular}{lccc}
\hline & Brand Loyalty & Digital_Marketing & Kepuasan_Nasabah \\
\hline BL1 & 0,896 & & \\
BL3 & 0,824 & & \\
BL4 & 0,876 & & \\
BL6 & 0,875 & & \\
BL7 & 0,894 & & \\
BL8 & 0,760 & 0,822 & \\
DM2 & & 0,874 & \\
DM3 & & 0,871 & \\
DM4 & & 0,886 & \\
DM5 & & 0,912 & \\
DM6 & & & 0,725 \\
KN1 & & & 0,751 \\
KN2 & & & 0,861 \\
KN3 & & & 0,822 \\
KN4 & & & 0,835 \\
KN5 & & & \\
KN6 & & \\
\hline
\end{tabular}

Sumber : data primer diolah, 2021. 
Tabel 2 di atas menunjukkan bahwa semua indikator telah memiliki nilai diatas 0,7 sehingga semua indikator dalam penelitian ini dapat dikatakan valid secara statistik serta dapat digunakan dalam konstruk penelitian

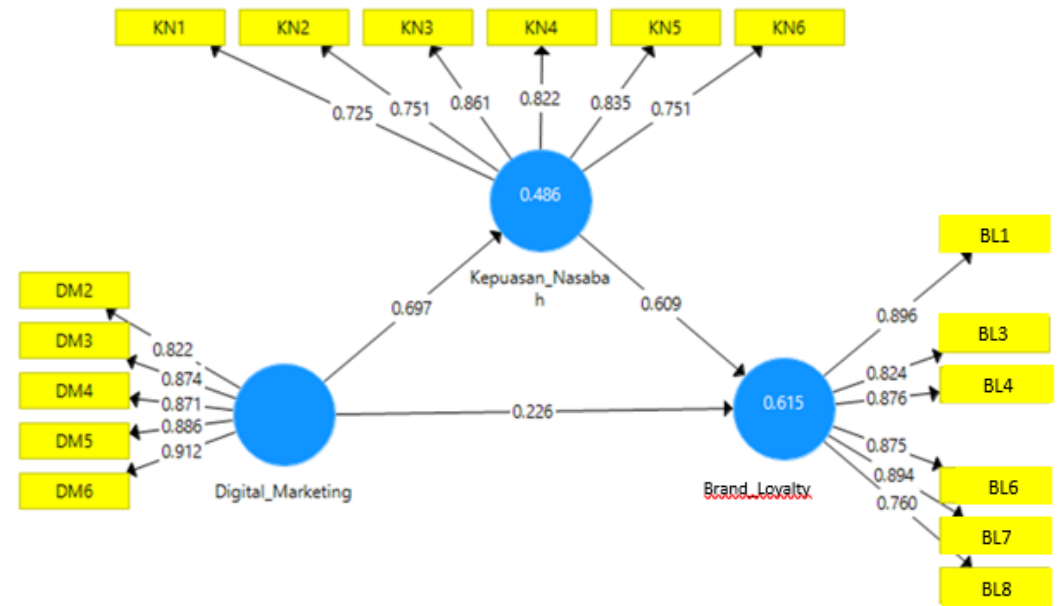

Gambar 2. Diagram Jalur Outer Model PLS

Construct Validity

Tabel 5 : Average Variance Extracted (AVE)

\begin{tabular}{ll}
\hline & Average Variance Extracted (AVE) \\
\hline Brand Loyalty & 0,732 \\
Digital_Marketing & 0,763 \\
Kepuasan_Nasabah & 0,628 \\
\hline
\end{tabular}

Sumber: data primer diolah, 2021.

Berdasarkan Tabel 5 maka dapat diketahui bahwa nilai AVE pada setiap variabel dalam model analisis penelitian ini telah memiliki nilai construct validity yang baik, yaitu nilai AVE lebih besar dari 0,5.

\section{Discriminant Validity}

Tabel 6 : Cross Loading

\begin{tabular}{llll}
\hline & Brand Loyalty & Digital_Marketing & Kepuasan_Nasabah \\
\hline BL1 & 0,896 & 0,535 & 0,622 \\
BL3 & 0,824 & 0,521 & 0,639 \\
BL4 & 0,876 & 0,587 & 0,635 \\
BL6 & 0,875 & 0,579 & 0,78 \\
BL7 & 0,894 & 0,588 & 0,703 \\
BL8 & 0,76 & 0,528 & 0,52 \\
DM2 & 0,473 & 0,822 & 0,597 \\
DM3 & 0,67 & 0,874 & 0,639 \\
DM4 & 0,503 & 0,871 & 0,556 \\
DM5 & 0,638 & 0,886 & 0,621 \\
DM6 & 0,531 & 0,912 & 0,625 \\
KN1 & 0,75 & 0,449 & 0,725 \\
KN2 & 0,448 & 0,424 & 0,751 \\
KN3 & 0,579 & 0,537 & 0,861 \\
\hline
\end{tabular}




\begin{tabular}{llll}
\hline KN4 & 0,553 & 0,499 & 0,822 \\
KN5 & 0,661 & 0,616 & 0,835 \\
KN6 & 0,593 & 0,724 & 0,751 \\
\hline
\end{tabular}

Sumber: data primer diolah, 2021

Tabel 6 menunjukkan bahwa nilai masing-masing indikator di suatu konstruk lebih tinggi dibandingkan dengan konstruk lain dan mengumpul pada satu konstruk tersebut. Maka dalam penelitian ini dapat dikatakan memiliki discriminant validity yang baik

\section{Composite Reliability}

Tabel 7 : Composite Reliability dan Cronbach's alpha

\begin{tabular}{lrrr}
\hline & Cronbach's Alpha & rho_A & Composite Reliability \\
\hline Brand Loyalty & 0,926 & 0,933 & 0,942 \\
Digital_Marketing & 0,922 & 0,927 & 0,942 \\
Kepuasan_Nasabah & 0,881 & 0,886 & 0,91 \\
\hline
\end{tabular}

Sumber: data primer diolah, 2021.

Berdasarkan Tabel 7 dapat diketahui bahwa seluruh konstruk dalam penelitian ini memiliki nilai Cronbach"s alpha $\geq 0,6$ dan nilai Composite reliability $\geq 0,7$, maka dapat dikatakan bahwa semua konstruk adalah reliable. Hal ini dapat diartikan bahwa masingmasing konstruk dalam model penelitian memiliki konsistensi internal dalam uji reliabilitas instrumen

\section{c. Evaluasi Model Struktural (Inner Model)}

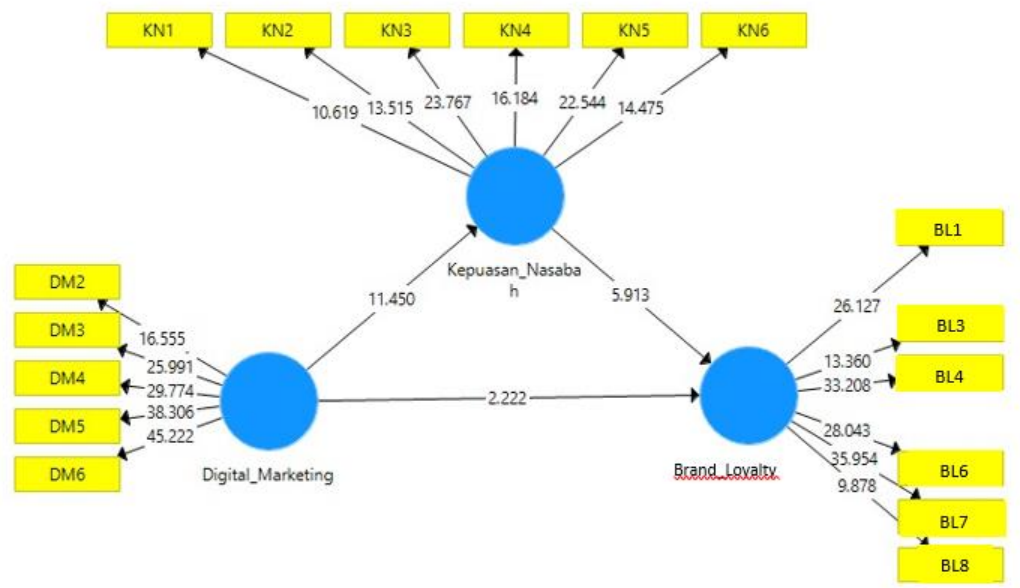

Gambar 3. Diagram Jalur Outer Model.

\section{Koefisien Determinasi}

Tabel 8 : R-Square

\begin{tabular}{lll}
\hline & R Square & R Square Adjusted \\
\hline Brand Loyalty & 0,615 & 0,608 \\
Kepuasan_Nasabah & 0,486 & 0,482 \\
\hline
\end{tabular}

Sumber: data primer diolah, 2021

Berdasarkan nilai $R$-square yang telah ditampilkan pada tabel 8 dan setelah dikalikan dengan $100 \%$ maka didapat nilai koefesien determinasi dari masing masing 
variabel adalah sebesar 61,5\% untuk variabel brand loyalty dan 48,6 \% untuk variable kepuasan nasabah. Hasil tersebut menunjukkan bahwa nilai koefisien determinasi brand loyalty berpengaruh pada penelitian ini sebesar $61,5 \%$, sedangkan $38,5 \%$ sisanya dijelaskan oleh variabel lain diluar model penelitian dan nilai koefisien determinasi dari variabel kepuasan nasabah sebesar $48,6 \%$ berpengaruh pada penelitian ini, sedangkan sisanya sebesar 51,4\% dijelaskan oleh variabel lain diluar model penelitian.

\section{Predictive Relevance}

Predictive relevance pada model struktural digunakan untuk mengukur seberapa baik nilai observasi dihasilkan oleh model dan juga estimasi parameternya (Ghozali, 2019). Nilai dari predictive relevance dapat diketahui melalui perhitungan $Q$-square sebagai berikut:

$$
\begin{aligned}
\mathrm{Q} 2 & =1-\left(\left(1-\mathrm{R}^{2}{ }_{1}\right) \times\left(1-\mathrm{R}^{2}{ }_{2}\right)\right) \\
& =1-((1-0.615) \times(1-0.486)) \\
& =1-(0.385 \times 0.514) \\
& =1-0.19789 \\
& =0.80211
\end{aligned}
$$

Berdasarkan hasil perhitungan $Q$-square diatas maka dapat dinyatakan bahwa model memiliki nilai predictive relevance sebesar 0.80211 atau $80,2 \%$, hal ini menunjukkan bahwa model anaisis memiliki predictive relevance yang baik.

\section{Goodness of Fit}

Adalah uji kecocokan atau kesesuaian antara hasil pengamatan (frekuensi pengamatan) tertentu dengan frekuensi yang diperoleh berdasarkan nilai harapannya (frekuensi teoritis). Nilai goodness of fit dapat diketahui melalui perhitungan berikut:

$$
\begin{aligned}
\text { Goodness of fit } & =\sqrt{\text { AVE X R }^{2}} \\
& =\sqrt{0.707 \times 0.550} \\
& =0.624
\end{aligned}
$$

Berdasarkan perhitungan tersebut, dapat diketahui nilai goodness of fit pada penelitian ini sebesar 0,624. GoF memiliki tiga kriteria, yaitu $\mathrm{GoF}=0,10$ bernilai kecil, GoF $=0,25$ bernilai sedang, $\mathrm{GoF}=0,36$ bernilai besar. Hasil perhitungan diatas menunjukkan jika performa gabungan antara model pengukuran dan model struktural

\begin{tabular}{|c|c|c|c|c|c|}
\hline & $\begin{array}{l}\text { Original } \\
\text { Sample } \\
(\text { O) }\end{array}$ & $\begin{array}{l}\text { Sample } \\
\text { Mean } \\
\text { (M) }\end{array}$ & $\begin{array}{l}\text { Standard } \\
\text { Deviation } \\
\text { (STDEV) }\end{array}$ & $\begin{array}{c}\text { t Statistics } \\
(\mid \text { O/STDEV } \mid)\end{array}$ & $\begin{array}{c}\mathbf{P} \\
\text { Values }\end{array}$ \\
\hline $\begin{array}{l}\text { Digital_Marketing }>\text { Brand } \\
\text { Loyalty } \\
\text { Digital_Marketing } \rightarrow>\end{array}$ & 0,226 & 0,221 & 0,113 & 2,222 & 0,046 \\
\hline $\begin{array}{l}\text { Kepuasan_Nasabah } \\
\text { Kenuasan_Nasabah }->\text { Brand }\end{array}$ & 0,697 & 0,697 & 0,068 & 11,450 & 0,000 \\
\hline $\begin{array}{l}\text { Loyalty } \\
\text { Lepran }\end{array}$ & 0,609 & 0,613 & 0,108 & 5,913 & 0,000 \\
\hline
\end{tabular}
memiliki nilai diatas 0,36 . Hal ini menjelaskan bahwa data empiris cocok atau sesuai dengan model (tidak ada perbedaan antara model dengan data sehingga model data dikatakan fit) (Ghozali, 2019).

\section{d. Pengujian Hipotesis}

Hasil pengujian hipotesis ditunjukkan pada tabel 9 adalah sebagai berikut :

Tabel 9. Path Coefficients

Sumber: data primer diolah, 2021. 
Berdasarkan hasil uji path coefficient pada tabel 9 diatas dapat disimpulkan bahwa penelitian ini memiliki nilai original sample yang positif sehingga hubungan antar variable dalam penelitian ini adalah hubungan positif dan signifikan yang ditandai dengan nilai $t$-statistic lebih besar dari 1,96 dan nilai $p$-value kurang dari 0,05

\section{e. Uji Mediasi}

Tabel 10 : Specific Indirect Effects

\begin{tabular}{cccccc}
\hline & $\begin{array}{c}\text { Original } \\
\text { Sample }(\boldsymbol{O})\end{array}$ & $\begin{array}{c}\text { Sample } \\
\text { Mean } \\
(\boldsymbol{M})\end{array}$ & $\begin{array}{c}\text { Standard } \\
\text { Deviation } \\
(\text { STDEV })\end{array}$ & $\begin{array}{c}\boldsymbol{t} \\
\text { Statistics }\end{array}$ & P Values \\
\hline $\begin{array}{c}\text { Digital_Marketing -> } \\
\text { Kepuasan_Nasabah }> \\
\text { Brand Loyalty }\end{array}$ & 0,425 & 0,424 & 0,076 & 5,604 & 0,000 \\
\hline
\end{tabular}

Sumber: data primer diolah, 2021.

Dapat dilihat dari tabel 10 bahwa hubungan digital marketing terhadap brand loyalty yang dimediasi oleh kepasan nasabah masih signifikan dengan nilai $\mathrm{t}$ - statistic $5.604<1.96$, hal ini berarti bahwa kepuasan nasabah berperan sebagai partial control dalam hubungan antara digital marketing dengan brand loyalty. Partial control berarti bahwa dalam hubungan antar variabel terdapat hubungan langsung dan tidak langsung (Garson, 2016). Pengaruh signifikansi dapat dilihat dari hasil path koefisien yang menunjukkan nilai T-statistik sebesar 5,604 $\geq 1.96$ dan nilai p-value $0.000 \leq 0,05$. Nilai t sebesar 5,604 nilai tesebut lebih besar dari 1,96 yang berarti bahwa parameter mediasi tersebut signifikan. Maka kepuasan nasabah mampu memediasi secara signifikan hubungan antara digital marketing dan brand loyalty.

\section{PEMBAHASAN}

\section{Pengaruh Digital Marketing Terhadap Brand Loyalty}

Digital marketing memiliki pengaruh positif dan signifikan terhadap brand loyalty. Pengaruh signifikansi dapat dilihat dari hasil path koefisien yang menunjukkan nilai $t$ statistic sebesar $2,222 \geq 1,96$ dan nilai $p$-value $0.046 \leq 0,05$. Penggunaan media digital dalam memasarkan produk perbankan dapat memberikan banyak keuntungan karena keunggulan yang dimiliki teknologi digital memungkinkan terjadinya komunikasi dua arah secara instan antara penyedia layanan perbankan dan nasabahnya, dimana nasabah dapat memilih, memesan, menanggapi bahkan mengajukan komplain secara langsung dimanapun dan kapanpun.

Hal yang penting yang perlu diperhatikan dari keunggulan teknologi digital tersebut adalah dalam hal tingginya frekuensi komunikasi atau interaksi yang terjadi antara pihak bank dan nasabahnya dengan proses distribusi informasi yang cepat, yang menunjukkan adanya komunikasi merek dengan frekuensi tinggi. Komunikasi merek merupakan salah satu penyebab seorang nasabah akan menjadi loyal dan percaya terhadap merek sehingga bersedia untuk membayar suatu produk dengan harga berapapun. Loyalitas merek menunjukkan adanya keterikatan antara pelanggan dengan sebuah merek. Hal ini sejalan dengan penelitian yang dilakukan oleh Kim dan Adler, (2011); Murtiningsih \& Murad, (2016).

\section{Pengaruh Digital Marketing Terhadap Kepuasan Nasabah}

Digital marketing memiliki pengaruh positif dan signifikan terhadap kepuasan nasabah. Pengaruh signifikansi dapat dilihat dari hasil path koefisien yang menunjukkan 
nilai t-statistik sebesar $11,450 \geq 1,96$ dan nilai p-value $0.000 \leq 0,05$. Nilai koefisien pengaruh variabel digital marketing terhadap kepuasan nasabah sangat tinggi. Hal ini menunjukkan bahwa digital marketing dianggap merupakan bentuk pemasaran yang paling efektif dibandingkan dengan pemasaran daam bentuk yang lain dimana dengan digital marketing dapat membeti kenyamanan, kemudahan, serta kecepatan bagi konsumenn dalam bertransaksi

Sebagaimana kita ketahui kepuasan pelanggan adalah suatu keadaan dimana kegunaan dari suatu produk atau jasa dapat memenuhi atau bahkan melebihi harapan dan eskpektasi pelanggan, maka strategi digital marketing yang mampu memenuhi empat hal di atas akan menyebabkan nasabah Bank Jateng Cabang Wonosobo akan merasa puas, terutama kepuasan dalam komunikasi, karena digital marketing pada dasarnya merupakan strategi yang diterapkan dalam hal mengomunikasikan merek (produk dan jasa) dari sebuah produsen/penjual/perusahaan terhadap pelanggan melalui saluran komunikasi digital (misalnya, internet, email, mobile phones, TV digital) dan teknologi informasi. Hasil penelitian ini sejalan dengan penelitian yang telah dilakukan oleh (Desereacute \& Thakane, 2013; Stanley \& Chinelo, 2017; dan Pradiatiningtyas et al., 2020).

\section{Pengaruh Kepuasan Nasabah Terhadap Brand Loyalty}

Kepuasan nasabah memiliki pengaruh positif dan signifikan terhadap brand loyalty. Pengaruh signifikansi dapat dilihat dari hasil path koefisien yang menunjukkan nilai Tstatistik sebesar 5,913 $\geq 1,96$ dan nilai p-value $0.000 \leq 0,05$. Nasabah setia Bank Jateng Cabang Wonosobo dapat memberikan rekomendasi yang positif, lebih sering membeli, mencoba produk baru yang dibuat oleh bank maupun memberikan saran yang tulus kepada bank untuk menjadi lebih baik lagi. Bank Jateng Cabang Wonosobo harus memastikan mereka dapat memuaskan nasabahnya karena ketika nasabah puas dengan produk/merek, mereka cenderung merekomendasikan produk kepada orang lain, kecil kemungkinannya untuk beralih ke merek alternatif lain, dan cenderung melakukan pembelian ulang, dimana hal tersebut akan menyebabkan keuntungan bagi organisasi. Hasil ini sejalan dengan penelitian yang dilakukan oleh Awan \& Rehman (2014); Dewi \& Yasa (2021); dan Pramita (2019). Semakin meningkat kepuasan nasabah maka akan meningkatkan perilaku loyalitas mereka terhadap merek.

\section{Pengaruh Mediasi Kepuasan Nasabah Terhadap Hubungan Digital Marketing dan Brand Loyalty.}

Variabel kepuasan nasabah mampu memediasi hubungan digital marketing terhadap brand loyalty dengan nilai $\mathrm{t}$ - statistic $5.604<1.96$. Artinya kepuasan nasabah dapat memediasi pengaruh digital marketing terhadap loyalitas merek (brand loyalty), pengaruh digital marketing terhadap loyalitas merek (brand loyalty) mempunyai pengaruh tidak langsung yang signifikan melalui kepuasan nasabah. Digital marketing tidak akan dapat menjadi faktor yang dipertimbangkan dalam peningkatan brand loyalty. Jika nasabah merasakan ketidakamanan bertransaksi dan tidak merasakan kepuasan pelayanan dari Bank Jateng Cabang Wonosobo maka hal tersebut menjadi pertimbangan mereka untuk memutuskan berpindah ke bank lain. Hasil ini sejalan dengan penelitian yang telah dilakukan oleh Kelly, dkk. (2010); Schau dkk. (2009); dan Lee dkk.(2014).

\section{PENUTUP}

\section{Kesimpulan}


a) Digital marketing mempunyai pengaruh yang positif dan signifikan terhadap brand loyalty. Dari hasil jawaban responden menunjukkan bahwa langkah-langkah interaktif yang menguntungkan di media sosial adalah yang paling signifikan menjadi pendorong peningkatan loyalitas merek diikuti oleh relevansi konten, popularitas konten digital dibandingkan dengan bank-bank lain, dan muncul di berbagai platform media sosial dan menyediakan aplikasi.

b) Digital marketing mempunyai pengaruh yang positif dan signifikan terhadap kepuasan nasabah. Pengaruhnya cukup besar. Dari hasil jawaban responden menunjukkan bahwa factor kemudahan adalah indicator yang mempunyai tanggapan yang cukup tinggi, dimana para nasabah akan semakin merasakan kepuasan apabila relative mudah, nyaman dan efisien dalam mendapatkan produk atau pelayanan. Diikuti dengan kualitas produk yaitu dimana tanggapan nasabah merasa puas dengan hasil evaluasi, mereka menunjukkan bahwa produk yang mereka gunakan berkualitas. Demikian pula dengan dukungan kualitas pelayanan dan factor emosional yang dibangun oleh Bank Jateng Cabang Wonosobo.

c) Kepuasan nasabah mempunyai pengaruh yang positif dan sgnifikan terhadap brand loyalty. Jika kepuasan nasabah meningkat maka akan semakin meningkatkan loyalitas mereka terhadap merek. Reputasi Bank Jateng Cabang Wonosobo sebagai banknya orang Jawa Tengah sudah sangat kuat sehingga sudah menjamin adanya kepercayaan (trust) dari para nasabah.

d) Kepuasan nasabah mampu memediasi hubungan digital marketing dengan brand loyalty. Dari hasil perhitungan, pengaruh digital marketing menjadi semakin meningkat terhadap brand loyalty melalui peran mediasi kepuasan nasabah.

\section{Saran}

a) Pertama-tama, perusahaan yang ingin menjalankan kampanye media sosial yang efektif harus mempertimbangkan manfaat, nilai, keuntungan yang mereka tawarkan kepada nasabah dalam kampanye mereka, apa yang membuat konsumen lebih mungkin untuk menjadi loyal terhadap merek mereka dalam hal ini Bank Jateng Capem Wonosobo. Loyalitas merek konsumen juga dipengaruhi secara positif oleh platform dan aplikasi yang berbeda dari platform dan aplikasi yang ditawarkan oleh merek (Bank Jateng Cabang Wonosobo) di media sosial, yang mungkin menyiratkan bahwa konsumen menanyakan alasan kreatif, variasi, dan perbedaan untuk terlibat dengan merek di media sosial. Dengan demikian, perusahaan dapat bekerja untuk menciptakan aplikasi yang lebih menarik, partisipatif, menarik, kertas juga menganalisis jenis konten apa yang dibagikan dan disukai oleh pengguna media sosial.

b) Penyedia jasa dalam hal ini Bank Jateng Cabang Wonosobo sebaiknya membangun hubungan dengan nasabah secara pribadi, karna hal ini sangat penting untuk membangun nasabah yang benar-benar setia. Jika perusahaan ingin orang-orang berkomitmen pada merek perusahaannya, maka perusahaan harus mempersonalisasi komunikasi dengan nasabah sebanyak mungkin.

c) Nasabah Bank Jateng Cabang Wonosobo mengandalkan individu pemberi layanan perbankan untuk memiliki keterampilan dan pengalaman untuk melakukan apa yang mereka lakukan dengan cara terbaik.

d) Perusahaan dalam hal ini Bank Jateng Cabang Wonosobo harus terus memperbaharui diri tentang apa yang diminati pelanggan, aktivitas mereka, dan perspektif saat ini dalam hidup. Perusahaan dapat melakukan penelitian atau pengamatan kualitatif untuk memahami gaya hidup nasabah dan mentransfer 
pengetahuan ini pada platform media pemasaran digital. Dampak dari mulut ke mulut dalam pemasaran adalah tidak dapat diabaikan, terutama di lingkungan online. Oleh karena itu, pihak perusahaan dapat menyediakan insentif kepada para pengguna media digital Bank Jateng untuk menyebarkan berita tentang kehadiran, kampanye, dan konten mereka di media digital di antara teman sebaya. Pihak Bank Jateng Cabang Wonosobo juga dapat melihat pemimpin opini di pasar sasaran mereka dan mempekerjakan mereka yang bertujuan untuk membicarakan kampanye mereka dan menarik orang untuk terlibat dengan merek mereka di media digital.

\section{DAFTAR PUSTAKA}

Al-msallam, S. (2015). Customer Satisfaction and Brand Loyalty in the Hotel Industry. European Scientific Journal, ESJ, 11(10). https://doi.org/10.5281/zenodo.3461457

Ali, B. J., Saleh, P. F., Akoi, S., Abdulrahman, A. A., Muhamed, A. S., Noori, H. N., \& Anwar, G. (2021). Impact of Service Quality on the Customer Satisfaction: Case study at Online Meeting Platforms. International Journal of Engineering, Business and Management, 5(2), 65-77. https://doi.org/10.22161/ijebm.5.2.6

Amelda, B., Alamsjah, F., \& Elidjen, E. (2021). Does The Digital Marketing Capability of Indonesian Banks Align with Digital Leadership and Technology Capabilities on Company Performance? CommIT (Communication and Information Technology) Journal, 15(1), 9-17. https://doi.org/10.21512/commit.v15i1.6663

Andriyani, M., \& Ardianto, R. (2020). Pengaruh Kualitas Layanan dan Kualitas Produk Terhadap Kepuasan Nasabah Bank. EKOMABIS: Jurnal Ekonomi Manajemen Bisnis, 1(02), 133-140. https://doi.org/10.37366/ekomabis.v1i02.73

Arum Wahyuni Purbohastuti. (2017). Vol. 12, No. 2, Oktober 2017. Ekonomika, 12(2), 212-231.

Ati, A., Shabri, M., Azis, N., \& Hamid, A. (2020). Mediating the effects of customer satisfaction and bank reputation on the relationship between services quality and loyalty of islamic banking customers. Malaysian Journal of Consumer and Family Economics, 25(November), 28-61.

Awan, A., \& Rehman, A. (2014). Impact of Customer Satisfaction on Brand loylty - an Empirical Analysis of Home Appliances in Pakistan. Journal of Chemical Information and Modeling, 2(8), 18-32. http://www.eajournals.org/wpcontent/uploads/Impact-Of-Customer-Satisfaction-On-Brand-Loyalty-AnEmpirical-Analysis-Of-Home-Appliances-In-Pakistan..pdf

Bisschoff, C. (2020a). Measuring and managing brand loyalty of banks' clients. Banks and Bank Systems, 15(3), 160-170. https://doi.org/10.21511/bbs.15(3).2020.14

Bisschoff, C. (2020b). Measuring and managing brand loyalty of banksclients. Banks and Bank Systems, 15(3), 160.

Brakus, J. J., Schmitt, B. H., \& Zarantonello, L. (2009). Brand Experience: What Is It? How Is It Measured? Does It Affect Loyalty? Journal of Marketing, 73(3), 52-68. https://doi.org/10.1509/jmkg.73.3.52

Casteran, G., Chrysochou, P., \& Meyer-Waarden, L. (2019). Brand loyalty evolution and the impact of category characteristics. Marketing Letters, 30(1), 57-73.

Desereacute, K., \& Thakane, K. (2013). Reflecting on Information and Communication Technology (ICT) in marketing from a marketers and student perspective. African Journal of Business Management, 7(31), 3098-3108. https://doi.org/10.5897/ajbm2013.7054 
Dwivedi, Y. K., Ismagilova, E., Hughes, D. L., Carlson, J., Filieri, R., Jacobson, J., Jain, V., Karjaluoto, H., Kefi, H., Krishen, A. S., Kumar, V., Rahman, M. M., Raman, R., Rauschnabel, P. A., Rowley, J., Salo, J., Tran, G. A., \& Wang, Y. (2021). Setting the future of digital and social media marketing research: Perspectives and research propositions. International Journal of Information Management, 59(July 2020), 102168. https://doi.org/10.1016/j.ijinfomgt.2020.102168

Erdoğmuş, İ. E., \& Çiçek, M. (2012). The Impact of Social Media Marketing on Brand Loyalty. Procedia - Social and Behavioral Sciences, 58(September 2014), 13531360. https://doi.org/10.1016/j.sbspro.2012.09.1119

Fandi, T., \& Gregorius, C. (2012). Pemasaran Strategik Edisi 2. Yogyakarta: CV. Andi.

Fida, B. A., Ahmed, U., Al-Balushi, Y., \& Singh, D. (2020). Impact of Service Quality on Customer Loyalty and Customer Satisfaction in Islamic Banks in the Sultanate of Oman. SAGE Open, 10(2). https://doi.org/10.1177/2158244020919517

Garepasha, A., Aali, S., Zendeh, A. B., \& Iranzadeh, S. (2020). Dynamics of online relationship marketing: Relationship quality and customer loyalty in Iranian banks. Revista Brasileira de Gestao de Negocios, 22(1), 140-162. https://doi.org/10.7819/rbgn.v22i1.4043

Gazi, M. A. I., Rahaman, M. A., Hossain, G. M. A., Ali, M. J., \& Mamoon, Z. R. (2021). An Empirical Study of Determinants of Customer Satisfaction of Banking Sector: Evidence from Bangladesh. Journal of Asian Finance, Economics and Business, 8(2), 497-503. https://doi.org/10.13106/jafeb.2021.vol8.no2.0497

Giovanis, A. N., \& Athanasopoulou, P. (2018). Consumer-brand relationships and brand loyalty in technology-mediated services. Journal of Retailing and Consumer Services, 40(July 2016), 287-294. https://doi.org/10.1016/j.jretconser.2017.03.003

Glowa, T. (2014). Measuring Customer Satisfaction: Exploring Customer Satisfaction's Relationship with Purchase Behavior. BookBaby.

Hamad, H. (2018). Customer satisfaction in banking sector : the case in north Iraq, city of Erbil. March, 71. https://doi.org/10.13140/RG.2.2.31537.71522

Hendrawan, A., Sucahyowati, H., Cahyandi, K., Indriyani, \& Rayendra, A. (2019). Pengaruh Marketing Digital Terhadap Kinerja Penjualan Produk UMKM Asti Gauri di Kecamatan Bantasari Cilacap. Jurnal Administrasi Dan Kesekretarisan, 4(1), 53-60. http://www.jurnal.stikstarakanita.ac.id/index.php/JAK/article/view/189/136

Hudson, S., Huang, L., Roth, M. S., \& Madden, T. J. (2016). The influence of social media interactions on consumer-brand relationships: A three-country study of brand perceptions and marketing behaviors. International Journal of Research in Marketing, 33(1), 27-41. https://doi.org/10.1016/j.ijresmar.2015.06.004

Jiang, H., \& Zhang, Y. (2016). An investigation of service quality, customer satisfaction and loyalty in China's airline market. Journal of Air Transport Management, 57, 80-88. https://doi.org/10.1016/j.jairtraman.2016.07.008

Kadarisman, H., \& Ariyani, N. (2021). Hubungan e-Word of Mouth dan Citra Merk dengan Minat Membeli pada Perbankan Syariah di Indonesia. Management \& Accounting Expose, 1(2), 1-11. https://doi.org/10.36441/mae.v1i2.84

Kannan, P. K., \& Li, H. "Alice." (2017). Digital marketing: A framework, review and research agenda. International Journal of Research in Marketing, 34(1), 22-45. https://doi.org/10.1016/j.ijresmar.2016.11.006

Keller, K. L., \& Kotler, P. (2012). Dirección de marketing.

Khandelwal, M., Sharma, A., Deepika Varshney, D., \& Arti Dagur, A. (2018). To analyze 
Consumer Satisfaction level in Digital Content Marketing with Emphasis on Shopping Websites. International Journal of Engineering \& Technology, 7(3.12), 637. https://doi.org/10.14419/ijet.v7i3.12.16444

Kusuma, A. H. P., Sudirman, A., Purnomo, A., Aisyah, S., Sahir, S. H., Rumondang, A., Salmiah, S., Halim, F., Wirapraja, A., \& Napitupulu, D. (2020). Brand Management: Esensi, Posisi dan Strategi. Yayasan Kita Menulis.

Labrecque, L. I., vor dem Esche, J., Mathwick, C., Novak, T. P., \& Hofacker, C. F. (2013). Consumer power: Evolution in the digital age. Journal of Interactive Marketing, 27(4), 257-269. https://doi.org/10.1016/j.intmar.2013.09.002

M Anwar, S. (2019). Structural Equation Modeling (SEM) Berbasis Varian (Konsep Dasar dan Aplikasi Program Smart PLS 3.2. 8 Dalam Riset Bisnis).

Magotra, I., Sharma, J., \& Sharma, S. K. (2018). Investigating linkage between customer value and technology adoption behaviour: A study of banking sector in India. European Research on Management and Business Economics, 24(1), 17-26. https://doi.org/10.1016/j.iedeen.2017.11.001

Mangold, W. G., \& Faulds, D. J. (2009). Social media: The new hybrid element of the promotion mix. Business Horizons, 52(4), 357-365. https://doi.org/10.1016/j.bushor.2009.03.002

Murtiningsih, D., \& Murad, A. A. (2016). The Effect of Social Media Marketing To Brand Loyalty ( Case Study at the University of Budi Luhur Jakarta ). International Journal of Business and Management Invention, 5(5), 50-53.

Nambiar, B. K., Ramanathan, H. N., Rana, S., \& Prashar, S. (2019). Perceived Service Quality and Customer Satisfaction: A Missing Link in Indian Banking Sector. Vision, 23(1), 44-55. https://doi.org/10.1177/0972262918821228

Ngabiso, F., Radji, D. L., \& Kango, U. (2021). pengaruh citra merek (brand image) dan kepercayaan merek (brand trust) erhadap loyalitas merek (brand loyalty) pada produk air minum dalam kemasan merek aqua (studi pada konsumen AMDK merek aqua di kota Gorontalo). 4(1), 1-12.

Nuseir, M. T. (2016). Exploring the use of Online Marketing Strategies and Digital Media to Improve the Brand Loyalty and Customer Retention. International Journal of Business and Management, 11(4), 228. https://doi.org/10.5539/ijbm.v11n4p228

Oliver, R. L., \& Swan, J. E. (1989). Consumer Perceptions of Interpersonal Equity and Satisfaction in Transactions: A Field Survey Approach. Journal of Marketing, 53(2), 21. https://doi.org/10.2307/1251411

Omar, A. M., \& Atteya, N. (2020). The Impact of Digital Marketing on Consumer Buying Decision Process in the Egyptian Market. International Journal of Business and Management, 15(7), 120. https://doi.org/10.5539/ijbm.v15n7p120

Ong, C. H., Lee, H. W., \& Ramayah, T. (2018). Impact of brand experience on loyalty. Journal of Hospitality Marketing and Management, 27(7), 755-774. https://doi.org/10.1080/19368623.2018.1445055

Pakurár, M., Haddad, H., Nagy, J., Popp, J., \& Oláh, J. (2019). The service quality dimensions that affect customer satisfaction in the Jordanian banking sector. Sustainability (Switzerland), 11(4), 1-24. https://doi.org/10.3390/su11041113

Panjaitan, N. J. (2017). Politeness Strategies Of Male And Female Differences In Customer Services Mandiri Bank.pdf. Jurnal Politeknik Bisnis Indonesia; Vol 7 No 2 (2017). http://jurnal.murnisadar.ac.id/index.php/PBI/article/view/18

Prabowo, W. A. (2018). Pengaruh Digital Marketingterhadap Organizational Performance Denganintellectual Capital Dan Perceived Qualitysebagai Variabel 
Intervening Pada Industri Hotel Bintang Tiga Di Jawa Timur. Jurnal Manajemen Pemasaran, 12(2), 101-112. https://doi.org/10.9744/pemasaran.12.2.101-112

Pradiani, T. (2018). Pengaruh Sistem Pemasaran Digital Marketing Terhadap Peningkatan Volume Penjualan Hasil Industri Rumahan. Jurnal Ilmiah Bisnis Dan Ekonomi Asia, 11(2), 46-53. https://doi.org/10.32812/jibeka.v11i2.45

Pradiatiningtyas, D., Dewa, C. B., Safitri, L. A., \& Kiswati, S. (2020). The Effect of Satisfaction and Loyalty towards Digital Payment System Users among Generation $\mathrm{Z}$ in Yogyakarta Special Region. Journal of Physics: Conference Series, 1641(1). https://doi.org/10.1088/1742-6596/1641/1/012110

Pramita, P. E. G. (2019). Effect of Experience in Building Satisfaction, Trust and Loyalty. Jurnal Aplikasi Manajemen, 17(1), 76-86. https://doi.org/10.21776/ub.jam.2019.017.01.09

Rapitasari, D. (2016). Digital marketing Berbasis Aplikasi Sebagai Strategi Meningkatkan Kepuasaan Pelanggan. Jurnal Cakrawala, 10(2), 107-112. http://www.cakrawalajournal.org/index.php/cakrawala/article/view/36

Royle, J., \& Laing, A. (2014). The digital marketing skills gap: Developing a Digital Marketer Model for the communication industries. International Journal of Information Management, $\quad 34(2), \quad 65-73$. https://doi.org/10.1016/j.ijinfomgt.2013.11.008

Şahin, A., Zehir, C., \& Kitapçi, H. (2011). The effects of brand experiences, trust and satisfaction on building brand loyalty; an empirical research on global brands. Procedia - Social and Behavioral Sciences, 24, 1288-1301. https://doi.org/10.1016/j.sbspro.2011.09.143

Sari, I. P., Zahara, Z., \& Tadulako, U. (2021). LOYALITAS NASABAH BANK MANDIRI SYARIAH CABANG PALU. 7(1), 58-66.

Schau, H. J., Muñiz, A. M., \& Arnould, E. J. (2009). How brand community practices create value. Journal of Marketing, 73(5), 30-51. https://doi.org/10.1509/jmkg.73.5.30

Setyaning, A. N. A., \& Nugroho, S. S. (2020). The influence of website characteristics on customer satisfaction and E-WOM in Indonesia. Jurnal Siasat Bisnis, 24(2), 148-167. https://doi.org/10.20885/jsb.vol24.iss2.art5

Stanley, A., \& Chinelo, A. (2017). Www.Oaijse.Com Improving Customer Satisfaction Through Digital Marketing in the Nigerian Deposit Money Banks. Certified ISSN (Online), 2(3297), 2456-3293.

Sugiyono, S. (2010). Metode penelitian kuantitatif dan kualitatif dan R\&D. Alfabeta Bandung.

Sulaeman, E. (2015). Pengaruh Kualitas Pelayanan Terhadap Kepuasan Pelanggan (Studi Kasus Pada Charly VHT Family Karaoke Cabang Garut). Jurnal Manajemen Maranatha, 14(2), 115003.

Sundaram, V., Ramkumar, D., \& Shankar, P. (2017). Impact of E-Service Quality on Customer Satisfaction and Loyalty Empirical Study in India Online Business. Kinerja, 21(1), 48. https://doi.org/10.24002/kinerja.v21i1.1034

Supriyanto, A., Wiyono, B. B., \& Burhanuddin, B. (2021). Effects of service quality and customer satisfaction on loyalty of bank customers. Cogent Business \& Management, 8(1), 1937847. https://doi.org/10.1080/23311975.2021.1937847

Syafikarani, A. (2021). Analisis Strategi Digital Marketing dalam Pemasaran Album KPop (Studi Kasus: Weverse Shop - BTS). TANRA: Jurnal Desain Komunikasi Visual Fakultas Seni Dan Desain Universitas Negeri Makassar, 8(1), 1. 
https://doi.org/10.26858/tanra.v8i1.19114

Tabash, M. I., Albugami, M. A., Salim, M., \& Akhtar, A. (2019). Service quality dimensions of E-retailing of Islamic banks and its impact on customer satisfaction: An empirical investigation of Kingdom of Saudi Arabia. Journal of Asian Finance, Economics and Business, 6(3), 225-234. https://doi.org/10.13106/jafeb.2019.vol6.no3.225

Tarigan, J, \& Elsye Hatane, S. (2019). The Influence of Customer Satisfaction on Financial Performance Through Customer Loyalty and Customer Advocacy: A Case Study of Indonesia's Local Brand. KnE Social Sciences, 3(11), 270. https://doi.org/10.18502/kss.v3i11.4012

Tarigan, Josua, \& Sanjaya, R. (2013). Creative digital marketing. Elex Media Komputindo.

Veloutsou, C. (2015). Brand evaluation, satisfaction and trust as predictors of brand loyalty: the mediator-moderator effect of brand relationships. Journal of Consumer Marketing, 32(6), 405-421. https://doi.org/10.1108/JCM-02-2014-0878

Wang, Y. S., \& Tang, T. I. (2003). Assessing customer perceptions of website service quality in digital marketing environments. Journal of End User Computing, 15(3), 14-31. https://doi.org/10.4018/joeuc.2003070102

Yamin, A. Bin. (2017). Impact of Digital Marketing as a Tool of Marketing Communication: A Behavioral Perspective on Consumers of Bangladesh. American Journal of Trade and Policy, 4(3), 117-122. https://doi.org/10.18034/ajtp.v4i3.426

Yasmin, A., Tasneem, S., \& Fatema, K. (2015). Effectiveness of Digital Marketing in the Challenging Age: An Empirical Study. The International Journal of Management Science and Business Administration, 1(5), 69-80. https://doi.org/10.18775/ijmsba.1849-5664-5419.2014.15.1006

Young Kim, E., \& Kim, Y. (2004). Predicting online purchase intentions for clothing products. European Journal of Marketing, 38(7), 883-897. https://doi.org/10.1108/03090560410539302 